\title{
Non-small cell lung cancer cells survived ionizing radiation treatment display cancer stem cell and epithelial-mesenchymal transition phenotypes
}

Roberto Gomez-Casal ${ }^{1,2}$, Chitralekha Bhattacharya ${ }^{1,2}$, Nandita Ganesh$^{1}$, Lisa Bailey ${ }^{1}$, Per Basse ${ }^{1,3}$, Michael Gibson ${ }^{1,2}$, Michael Epperly ${ }^{1,2}$ and Vera Levina ${ }^{1,2,4^{*}}$

\begin{abstract}
lonizing radiation (IR) is used for patients diagnosed with unresectable non small cell lung cancer (NSCLC), however radiotherapy remains largely palliative due to radioresistance. Cancer stem cells (CSCs), as well as epithelialmesenchymal transition (EMT), may contribute to drug and radiation resistance mechanisms in solid tumors. Here we investigated the molecular phenotype of A549 and H460 NSCLC cells that survived treatment with IR (5Gy) and are growing as floating tumor spheres and cells that are maintained in a monolayer after irradiation. Non-irradiated and irradiated cells were collected after one week, seeded onto ultra low attachment plates and propagated as tumor spheres. Bulk NSCLC cells which survived radiation and grew in spheres express cancer stem cell surface and embryonic stem cell markers and are able to self-renew, and generate differentiated progeny. These cells also have a mesenchymal phenotype. Particularly, the radiation survived sphere cells express significantly higher levels of CSC markers (CD24 and CD44), nuclear $\beta$-catenin and EMT markers (Snail1, Vimentin, and N-cadherin) than nonirradiated lung tumor sphere cells. Upregulated levels of Oct-4, Sox2 and beta-catenin were detected in $\mathrm{H} 460$ cells maintained in a monolayer after irradiation, but not in radiation survived adherent A459 cells.

PDGFR-beta was upregulated in radiation survived sphere cells and in radiation survived adherent cells in both A549 and $\mathrm{H} 460$ cell lines. Combining IR treatment with axitinib or dasatinib, inhibitors with anti-PDFGR activity, potentiates the efficacy of NSCLC radiotherapy in vitro.

Our findings suggest that radiation survived cells have a complex phenotype combining the properties of CSCs and EMT. CD44, SNAIL and PDGFR-beta are dramatically upregulated in radiation survived cells and might be considered as markers of radiotherapy response in NSCLC.
\end{abstract}

Keywords: Non-small cell lung cancer, lonizing radiation, Cancer stem cell, Epithelial-mesenchymal transition

\section{Background}

Worldwide, lung cancer ranks highest in terms of both incidence and mortality [1]. Despite decades of research, systemic therapies fail to cure most lung cancers. Lung cancers are comprised of two major histological types: small-cell lung cancer (SCLC) and non-small-cell lung cancer (NSCLC, i.e., adenocarcinoma, squamous cell carcinoma, and large cell carcinoma). NSCLC comprises $85 \%$ of lung cancer cases and about $40 \%$ are unresectable [2].

Radiotherapy used for patients with unresectable NSCLC tumors remains largely palliative due to radioresistance

\footnotetext{
* Correspondence: levinav@upmc.edu

${ }^{1}$ University of Pittsburgh Cancer Institute, Pittsburgh, PA 15213, USA

${ }^{2}$ Department of Medicine, Pittsburg, PA 15213, USA

Full list of author information is available at the end of the article
}

$[1,3]$ which is possibly due to tumor heterogeneity in terms of cell of origin, pathology, etiology and molecular/genetic pathogenesis [4]. The existence of cancer stem/progenitor cells (CSCs) or tumor-initiating cells (TICs) reflects the cellular heterogeneity within solid tumors [5-7]. These cells are the undifferentiated cells with a high tumorigenic and self-renewal capacity, which have been identified in various human malignancies including breast, brain, prostate, pancreatic, colon and lung cancer [8-13]. CSCs express specific markers and stem cell genes and use common signaling pathways including Wnt/ $\beta$-catenin, Hedgehog and Notch [5-7]. CSCs can be enriched as a subpopulation of cells propagating as non-adherent spheres in medium suitable for tumor stem cells [9]. Evidence suggests that

\section{Biomed Central}


the failure of the treatment may be due to the existence of CSCs which are resistant to chemo- and radiotherapy [14-16].

The cell surface markers CD133, CD44, CD166, as well as ABCG2 transporter and aldehyde dehydrogenase 1 family, member A1 (ALDHA1) protein, have also been reported as human lung CSC markers [12,13,17-20]. Hoechst 33342 dye excluding cells, termed as sidepopulation (SP) cells, has been described as CSCs in a variety of tumor types, including NSCLCs [21,22]. Oct-4 protein is also critically involved in the self renewal of undifferentiated embryonic stem cells and is frequently used as a marker for undifferentiated cells. We demonstrated that lung cancer stem cells that survived treatment with chemotherapeutic drugs express Oct-4 [13]. The role of these important putative stem traits in lung CSCs were confirmed in further studies [23-25]. The expression of CSC-related markers, after chemo and radiation therapy, significantly correlated with a poor prognosis in patients with NSCLC [26], however direct confirmation of the role of lung CSCs in NSCLC radioresistance is missing.

In cancers, epithelial-mesenchymal transition (EMT) is also associated with resistance to chemotherapeutic drugs and radiation [27,28]; epithelial tumor cells with ongoing EMT develop CSC traits [29,30]. EMT is an embryonic process leading to the loss of cell-cell contact, repression of E-cadherin expression and increased cell motility. EMT transition in epithelial cells leads to switching from E- cadherin to N- cadherin [31].

As epithelial cancer cells undergo EMT, they gain stemness, motility, invasiveness, drug resistance and angiogenic and metastatic ability. EMT is regulated by a network of transcription factors including Snail, Slug, Twist, Zeb, and others [29,30,32,33]. EMT can be activated by TGF- $\beta$ and other oncogenic pathways (e.g., Src, Ras, Notch) [32,34] and by tumor microenvironment stresses (e.g., hypoxia) [35,36]. IR promotes EMT in tumor cell lines via the activation of TFG $\beta$ signaling [37-40]. The alteration of the expression of the E cadherin/ $\beta$-catenin complex is an independent poor prognostic factor in human lung adenocarcinoma [41]. However, until now there have not been any studies that have elucidated the CSC and EMT characteristics of NSCLC cells that survived IR-treatment.

In the present study, we performed an extensive comparative phenotypic analysis of CSC and EMT marker expression in bulk naïve adherent NSCLC cells, in irradiation survived adherent cells, non-irradiated lung tumor sphere cells and radiation-survived NSCLC cells growing as tumor spheres using the High Content Screening Approach (ThermoFisher, Cellomics INC).

Our findings demonstrate the role of CSC and EMT in radiation survived tumor sphere cells and may lead to the identification of the new therapeutic targets.

\section{Materials and methods Cell lines}

The human A549 and H460 NSCLC cell lines were purchased from the American Type Culture Collection (ATCC). Cells were grown in culture media, as recommended by the ATCC, that was supplemented with 10\% FBS (Millipore Inc., Billerica, MA).

\section{Reagents}

Hoechst 33342 was purchased from Sigma-Aldrich (SigmaAldrich, St. Louis, MO). Fluorochrome-conjugated antibody against human CD44 was from Beckman Coulter (Fullerton, CA). Antibodies against PDGFR-a; PDGFR-beta, CD166 and Sox-2 were from R\&D Systems INC (Minneapolis, MN). Antibodies against CD24, Snail1, Twist1, Slug, $\mathrm{N}$-cadherin, Vimentin, Fibronectin, ALDH1A1 and pancytokeratin were from Abcam Inc. (Abcam, Cambridge, MA). Oct-4 and E-Cadherin antibodies were purchased from Cell Signaling Technology Inc., (Cell Signaling, Danvers, MA). CD133 antibody was obtained from Miltenyi Biotec (Germany). Alexa Fluor ${ }^{\circ}-488$ conjugated mouse antibody against human $\beta$-catenin were purchased from BD Biosciences Inc. (San Diego, CA). Secondary antibody conjugated with Alexa ${ }^{\circ}-488,-546$, and-680 was from Molecular Probes (Invitrogen, Carlsbad, CA).

The Tyrosine kinase inhibitors, Axitinib and Dasatinib, were purchased from LC Laboratories (Woburn, MA).

\section{Irradiation}

NSCLC cells were irradiated, as cell suspension or as monolayer, using the Shepherd Mark 168 Irradiator, (137Cs Irradiator) (JL Shepherd, San Fernando, CA, USA) dose rate of $70.6 \mathrm{rad} / \mathrm{min}$ at room temperature.

\section{In vitro clonogenic assays}

Exponentially growing $\mathrm{H} 460$ and A549 cells were harvested by exposure to trypsin and cell suspensions were irradiated using a ${ }^{137} \mathrm{Cs}$ gamma-ray source with doses ranging from 0 to $10 \mathrm{~Gy}$ and plated in 6 well plates, 500 cells per well. Cultures were incubated at $37^{\circ} \mathrm{C}$ in $5 \% \mathrm{CO}_{2}$. The next day, axitinib or dasatinib was added to the cultures at a final concentration of $1 \mu \mathrm{M}$. The culture media with inhibitors was changed every day. Seven days later the cells were fixed and stained with crystal violet; colonies $\geq 50$ cells were counted and the size of the colonies were measured (Gel Count colony counter, Oxford Optronix, Oxford, UK). Data was analyzed with linear quadratic and single-hit multi-target models [42].

\section{Culture of irradiated cells}

Cells were seeded at a density of $2 \times 10^{5}$ cells/well, in 12-well plates containing RPMI, supplemented with $10 \%$ FBS. After overnight incubation, cells were irradiated 
(0-10 Gy) and maintained at $37^{\circ} \mathrm{C}$ in the incubator with $5 \% \mathrm{CO}_{2}$. Medium replacement was done every third day with fresh medium.

To obtain adherent radiation survived cells, cells were kept in the plates for two weeks. To analyze EMT and CSC markers in adherent radiation survived cells, cells were harvested, counted and seeded into 96 well plates containing RPMI, supplemented with 10\% FBS. The next day, the cells were fixed, immunofluorescently stained and analyzed as described below. To analyze cell motility, adherent radiation survived cells were collected and seeded into 6 well plates containing RPMI, supplemented with $10 \%$ FBS and a wound healing assay was applied.

To generate radiation survived tumor sphere cells, seven days after IR treatment the cells were harvested, filtered, counted and used for lung tumor sphere assays.

\section{Culture of lung tumor spheres}

Suspension growth was assessed in methyl cellulose-based $(0.8 \% \mathrm{MC})$ medium as described [9,11]. Briefly, NSCLC cells and IR-survived cells were resuspended in $0.8 \% \mathrm{MC}$ based serum free medium (Stem Cell Technologies, Vancouver, Canada) and supplemented with $20 \mathrm{ng} / \mathrm{mL}$ EGF (BD Biosciences), bFGF and $4 \mu \mathrm{g} / \mathrm{mL}$ insulin (Sigma) and plated at 500-10000cells $/ \mathrm{mL}$ in ultra low attachment 24-96 well plates (Corning, Corning, NY) for 12 days. The medium was replaced or supplemented with fresh growth factors (EGF, bFGF $(20 \mathrm{ng} / \mathrm{mL})$ and insulin $(4 \mu \mathrm{g} / \mathrm{mL})$ ) twice a week. The tumor sphere growth was analyzed under a phase-contrast microscope with an $\times 10$ objective and counted from multiple wells.

\section{Self renewal}

In order to assess the self renewing potential of the cells, spheres of the first generation were collected by gentle centrifugation, dissociated into single cell suspensions, filtered through a $30 \mu \mathrm{m}$ filter and cultured in ultra low attachment plates in stem cell selective medium as described above. The tumor sphere growth was analyzed under a phase-contrast microscope with a $10 \times$ objective and counted from multiple wells. To generate spheres of the 3rd, 4th and 5th generations, the 2nd, 3rd and 4th generation tumor spheres were collected; the single cell suspensions were prepared and were replated. The tumor spheres were counted after 12 days.

\section{Differentiation}

Cells dissociated from spheres (third generation) were plated at $1 \times 10^{4}$ cells $/ \mathrm{mL}$ on 96 -well plates that were precoated with Collagen IV (BD Biosciences), in culture media supplemented with 10\% FBS and transferred into new plates when cultures reached confluence. To test the self renewing potential of differentiated cells, they were transferred into semisolid serum-free media supplemented with EGF, FGF and insulin and their ability to form tumor spheres was evaluated, as described above. To perform a phenotypic characterization of the cells, from spheres and after differentiation, the cells were seeded in 96 well plates $\left(5 \times 10^{3}\right.$ cells/well $)$ and stained with various antibodies as described above.

\section{Monolayer wound healing assay}

Cells were seeded into the six-well plates at high density and were cultured for 2 days to produce a monolayer. Cells were plated, scratched and monitored in the media supplemented with 10\% FBS. Confluent cell monolayers were then scratched using a plastic $10 \mu \mathrm{L}$-pipette tip as described [43]. Wounded monolayers were then washed four times with medium to remove cell debris and incubated in a culture medium supplemented with $10 \%$ FBS for $24 \mathrm{~h}$. Images were captured in 0, 2, 4, 6 and $24 \mathrm{~h}$ using a ZEISS (light) microscope Axiovert 40C (Hamamatsu).

\section{Cell staining procedure for cellomics arrayscan automated imaging}

Cells were fluorescently stained as previously described $[13,44]$. Briefly, cells grown in 96-well plates were fixed, washed with FACS buffer, incubated with antibodies against CD24, CD34, CD44, CD117, CD166, conjugated with FITC, PE or PC5 for $1 \mathrm{~h}$; fixed in 2\% PFA for 20 min, washed in PBS, and stained with Hoechst 33342. To test CD133, PDGFR $\alpha$, PDGFR $\beta$ and CXCR4 expression, cells were incubated with respective primary antibodies and then with secondary antibodies that were conjugated with Alexa 488, 546, or 680 fluorochromes (Molecular Probes/Invitrogen) for $1 \mathrm{~h}$. Cell nuclei were then stained with Hoechst 33342 at $2 \mu \mathrm{g} / \mathrm{ml}$ for $20 \mathrm{mi}-$ nutes to identify individual cells and to optimize focusing. To detect intracellular proteins, cells were fixed and permeabilazed and then stained for $ß$-catenin, Sox-2, Snail1, Twist1 and cytokeratins using primary and secondary antibodies conjugated with Alexa - 488, 546 or 680 dyes (Molecular Probes/Invitrogen) as described above. All incubation and fixation procedures were performed at room temperature.

\section{Cellomics array scan automated imaging}

The Cellomics ArrayScan HCS Reader (Cellomics/ ThermoFisher, Pittsburgh, PA) was utilized to collect information on the distribution of fluorescently labeled components in stained cells. The ArrayScan HCS system scans multiple fields in individual wells, acquiring and analyzing each of the cell images according to defined algorithms. The scanner is equipped with emission and excitation filters (XF93, Omega Optical, Brattleboro, VT, USA) for selectively imaging fluorescent signals. Data was captured, extracted and analyzed with ArrayScan II Data Acquisition and Data Viewer version 3.0 (Cellomics), 
Quattro Pro version 10.0.0 (Corel, Ottawa, Ontario, Canada) and MS Excel 2002 (Microsoft, Redmond, WA).

\section{Statistical analysis}

Experiments were performed at least three times. Comparisons between values were performed using a twotailed Student's t-test. For the comparison of multiple groups, a one- or two-way ANOVA test was applied. For all statistical analyses, the level of significance was set at a probability of 0.05 .

\section{Results}

Generation of NSCLC cells survived ionizing radiation and propagated as tumor spheres

A549 and H460 bulk NSCLC cells were treated with clinically relevant doses of IR (5.0 Gy) and cultured for one week. The majority of cells died by the fifth day and enlarged cells were seen with flattened, senescent-like morphology. Radiation survived cells started clonogenic growth (Figure 1A, top images).
On the seventh day after irradiation, the cells were collected, filtered and plated as single cell suspensions in stem-cell selective conditions: ultra-low attachment plates, serum free media supplemented with growth factors to form floating tumor spheres. As shown in Figure 1A, IR-survived A549 and H460 cells proliferated and generated floating clones or tumor spheres.

Growth as tumor spheres is considered to be a surrogate marker for stemness and self renewal ability in epithelial cancers [9]. The ability to form tumor spheres in low attachment growth conditions is a good index of the tumorforming potential of stem cells. We have analyzed the tumor sphere formation in the radiation survived adherent clones as well as the parental NSCLC cells. As shown in Figure $1 \mathrm{~B}$, the numbers of first generation tumor spheres which developed from adherent radiation survived cells, was significantly higher than the number of spheres which developed from non-irradiated parental NSCLC cells.

Next, we developed second and third generation tumor spheres using our published approach [13]. The
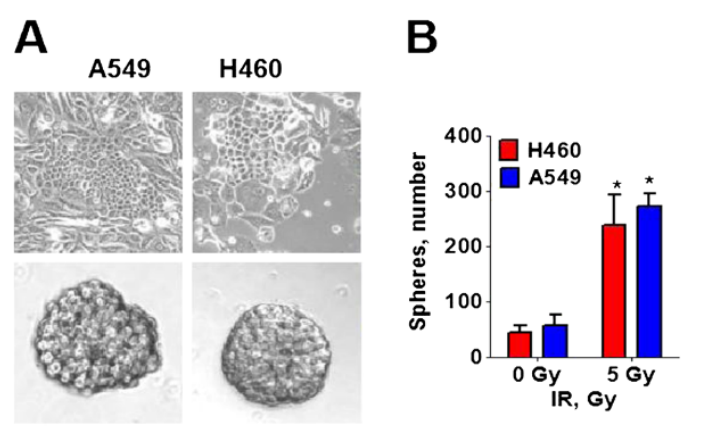

E

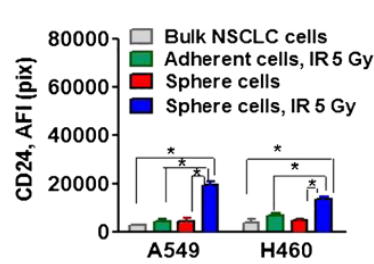

C

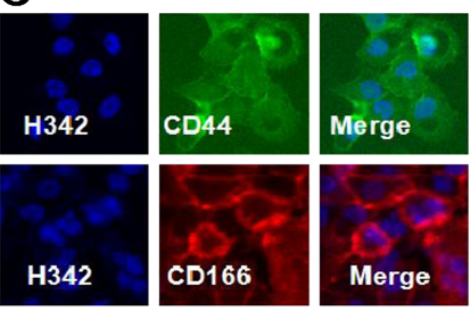

$\mathbf{F}$

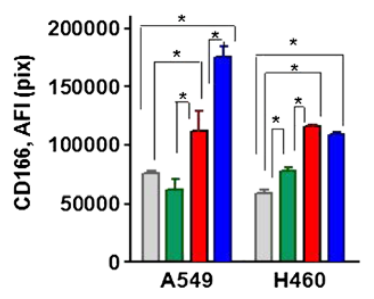

Figure 1 The radiation survived NSCLC cells express cancer stem cell markers. A549 and H460 cells were irradiated (5Gy) and cultured in adherent conditions for a week. Cells were collected and plated as single cell suspensions, in stem-cell selective conditions, to form floating tumor spheres. To obtain adherent radiation survived cells, cells were kept in the plates for two weeks after IR-treatment. Expressions of markers were tested in non-irradiated cells, adherent cells that survived IR treatment, non-irradiated sphere cells, and sphere cells that survived irradiation. (A) Morphology of adherent cells that survived IR treatment and spheres developed from IR-treated cells are shown. (B) Radiation survived cell populations are enriched in the tumor-sphere forming cells. Non-irradiated cells and radiation survived cells were harvested, and transferred into the stem cell selective conditions. 10 days later the tumor spheres, from the first generation, were counted under the microscope. The tumor spheres, from the first generation, were used to develop the tumor spheres for the second generation. The second generations of tumor spheres were used to develop the third generation spheres used for further study. (C-F) Analysis of CD44, CD24 and CD166 expression. Cells in 96-well plates were fixed, incubated with the respective antibody and stained with Hoechst33342. Cell images were acquired using the ArrayScan HCS Reader (40x objective) and analyzed using the Target Activation BioApplication Software Module. (C) The representative images of the A549 radiation survived sphere cells stained for CD44 and CD166 are shown. (D-F) The total average fluorescence intensities of CD24 (D), CD44 (E) and CD166 (F) in the non-irradiated cells (grey), IR- survived adherent cells (green), non-irradiated sphere cells (red) and in the IR-survived sphere cells (blue) are presented. The fluorescence intensities of respective lgG controls were subtracted. Each point presents average intensities (pixels) estimated for 3000 cells. 
third generation lung tumor spheres cells were used for further study.

In addition, A549 and H460 cells that survived IR treatment $(5.0 \mathrm{~Gy})$, in adherent monolayer cultures, were used in the comparative study.

\section{Analysis of lung cancer stem cell traits}

To determine whether the radiation survived cells have other intrinsic properties of stem cells, immunofluorescent staining and HCA and HCS analyses from Cellomics, ThermoFisher, for expression of CSC and embryonic transcription factors were used. The comparative analyses of CSC markers in non-irradiated NSCLC cells, radiation survived adherent cells, non-irradiated lung tumor sphere cells, and radiation survived cells growing in tumor spheres was performed (Figure 1C-F). Non-irradiated lung sphere cells, as well as radiation survived sphere cells, showed significant upregulation of CD44 and CD166, as compared with parental NSCLC cells in both cell lines, which corresponds to the previously identified phenotypic markers of human lung CSCs. CD44 expression was significantly higher in the radiation survived sphere cells than in non-irradiated sphere cells in both cell lines, whereas CD166 was significantly upregulated in sphere cells generated from IRtreated A549 cells. CD44 and CD166 levels were also higher in radiation survived adherent $\mathrm{H} 460$ cells, than in non-irradiated bulk $\mathrm{H} 460$ cells.

Interestingly, CD24 upregulation was observed only in radiation survived sphere cells and was not elevated in non-irradiated lung spheres cells or radiation survived adherent cells in comparison to bulk NSCLC cells in both cell lines (Figure 1D).

We next analyzed the expression of transcription factors correlating with stemness (beta- catenin, Oct-4, and Sox-2) in non-irradiated NSCLC cells, radiation survived adherent cells, non-irradiated sphere cells and in the radiation survived sphere cells (Figure 2). As shown for beta-catenin (Figure 2A), these transcription factors are mainly located in the nuclei of the cells. Beta-catenin upregulation has been detected in the radiation survived sphere cells in both cell lines (Figure 2B). A substantial increase in Oct-4 has been found only in A549 radiation survived sphere cells, whereas upregulation of the Sox-2 transcription factor has been observed only in H460 radiation survived sphere cells (Figure 2C-D). However, in
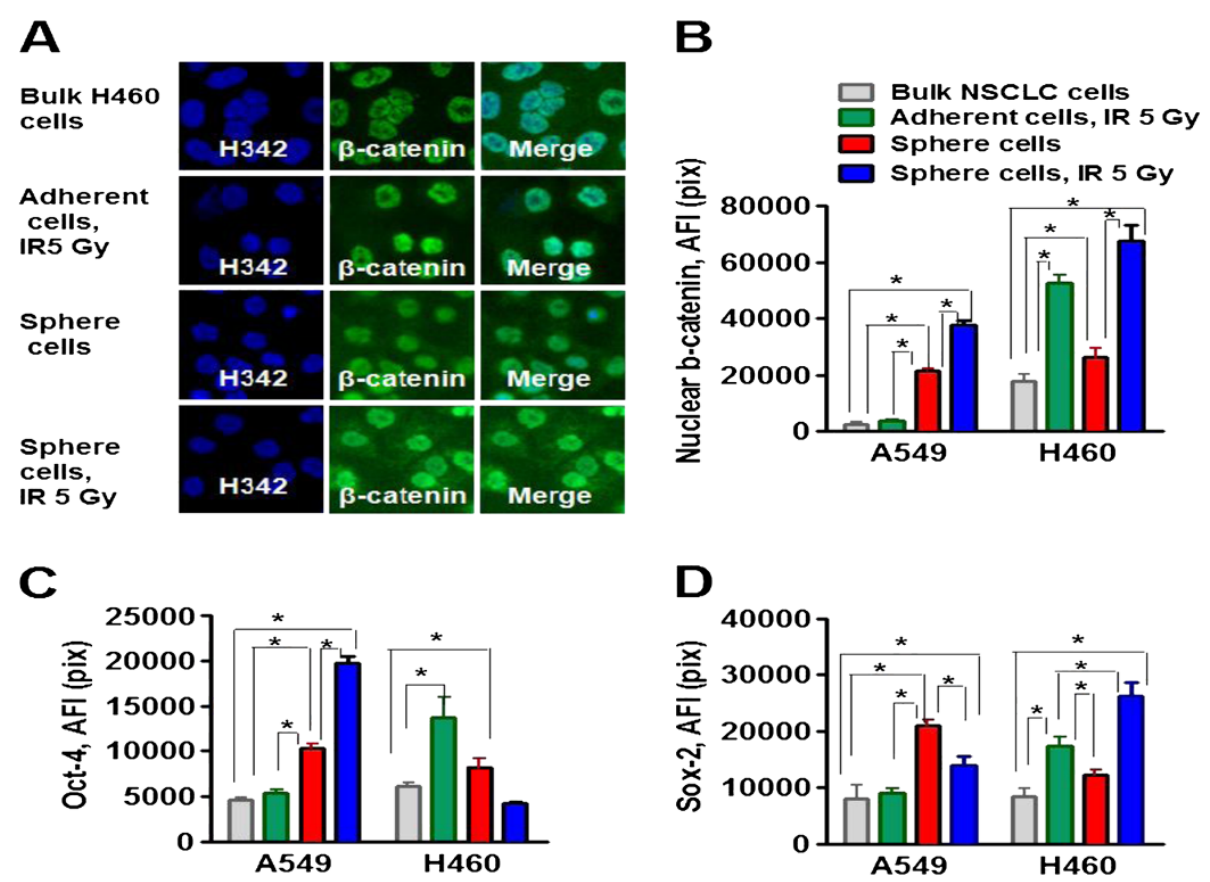

Figure 2 The radiation survived NSCLC cells show upregulation of beta-catenin, Oct-4 and Sox-2 transcription factors. Non-irradiated NSCLC cells, radiation survived adherent cells, non-irradiated sphere cells and radiation survived sphere cells were collected and seeded into collagen precoated 96-well plates. 8 hours later the cells were fixed, permeabelized and immunofluorescently stained for beta-catenin, Oct-4 and Sox-2. The cell nuclei were stained with Hoechst33342. Cell images were acquired using the Cellomics ArrayScan HCS Reader (40x objective) and analyzed using the Compartment Analysis BioApplication Software Module. (A) The representative images of parental non-irradiated H460 cells, radiation survived adherent cells, non-irradiated sphere cells and radiation survived sphere cells stained for beta-catenin are shown. (B-D) The total average fluorescence intensities of nuclear beta-catenin (B), Oct-4 (C) and Sox-2 (D) in the non-irradiated NSCLC cells (grey), in the radiation survived adherent cells (green), in the non-irradiated sphere cells (red) and in the radiation survived sphere cells (blue) are presented.

Fluorescence intensities of respective lgG controls were subtracted. Each point presents average intensities (pixels) estimated for 3000 cells. 
general, the elevated expression of two stemnessassociated transcription factors (e.g. $\beta$-catenin and Oct4 ; $\beta$-catenin and Sox-2) in radiation survived sphere cells suggests that these cells might have more pluripotent and aggressive phenotypes than non-irradiated lung tumor sphere cells. Radiation survived adherent H460 cells display upregulation of stemness-associated transcription factors, Oct-4, Sox2 and beta -catenin, whereas radiation survived adherent A549 cells have shown the same low level of these transcription factors as adherent nonirradiated bulk A549 cells.

Radiation survived sphere cells could be propagated for at least 10 passages after mechanical disaggregation of the spheres into a single cell suspension and replating into low-adherence conditions in serum-free media supplemented with growth factors. Limiting dilution experiments showed that the percentage of clonogenic cells, in spheres generated from IR -escapees, was $22 \%$ and $27 \%$ in cells derived from H460 and A549 cell lines, respectively, and did not change in subsequent passages.

If radiation- survived sphere cells were disaggregated and plated in collagen precoated plates with culture media supplemented 10\% FBS, they adhered and started proliferating. After four weeks of culture under adherent conditions in culture media supplemented with FBS, the cells differentiated and acquired an epithelial morphology with decreased expression of CD44, CD24 and CD166 (data not shown).

\section{Analysis of epithelial to mesenchymal transition (EMT) markers}

We studied a number of markers associated with EMT using immunofluorescent staining and the Compartment Analysis BioApplication Software Module from Cellomics which allows us to quantify fluorescence signals in nuclear and cytoplasm compartments of the cells.

Non-irradiated sphere cells, as well as radiation survived sphere cells, showed an upregulation of EMT-related transcription factor Snail1 as compared to adherent parental and IR treated H460 and A549 cells. However, the level of Snail1 expression was significantly higher in radiation survived sphere cells than in non-irradiated sphere cells (Figure 3A). Snail1 was detected in the nuclear and in the cytoplasm compartments of the cells (Figure 3B,C). In contrast, the up-regulation of the EMT-related transcription factor Twist was observed only in the radiation survived sphere cells originated from A549 cell line and Twist was mainly located in the cell nucleus (Figure 3D,E). Radiation survived sphere cells and non-irradiated sphere cells that originated from H460 cell line expressed the same low levels of Twist as the parental H460 cells (Figure 3D,F).

To further confirm the EMT phenotype of radiation survived sphere cells, we analyzed the expression of fibronectin, vimentin, N-cadherin, and E-cadherin Figure 4). As shown in Figure 4, non-irradiated sphere cells and radiation survived sphere cells demonstrated strong upregulation of vimentin and $\mathrm{N}$-cadherin when compared with the adherent bulk and IR treated cell populations, however, this EMT marker expression was significantly higher in radiation survived sphere cells than in non-irradiated sphere cells in both cell lines.

Fibronectin was elevated only in sphere cells and radiation survived sphere cells of the A459 cell line but not of the $\mathrm{H} 460$ cell line. In contrast, repression of E-cadherin expression was observed in radiation survived sphere cells when compared with bulk NSCLC cells and non-irradiated sphere cells (Figure 4) in A459 and also $\mathrm{H} 460$ cell lines.

\section{Analysis of cell migration}

Next, we tested whether EMT marker expression, in radiation survived sphere cells, was associated with increased cell motility. Migratory rates of non-irradiated NSCLC cells, radiation survived adherent cells, nonirradiated lung tumor sphere cells and radiation-survived cells growing in tumor spheres were monitored in an in vitro wound healing assay. As shown in Figure 5, sphere cells, non-irradiated and radiation survived, were able to reestablish a monolayer significantly faster than non-irradiated and radiation survived adherent $\mathrm{H} 460$ and A549 cells. For sphere cells, non-irradiated and radiation survived, wounds closure was complete at $24 \mathrm{~h}$ after the scratching, whereas adherent NSCLC cells did not complete wound healing at 24 hours. This data indicates that tumor spheres cells have a higher motility than adherent NSCLC cells.

\section{Analysis of CXCR4 and PDGFR receptors expression}

Upregulation of CXCR4 is functionally crucial for the maintenance of stemness in drug-resistant NSCLC cells $[13,45]$. Platelet-derived growth factor receptor (PDGFR) signaling plays a crucial role in specifying the mesenchymal stem cell (MSC) commitment to mesenchymal lineages [46]. Therefore, we investigated CXCR4, PDGFR $\alpha$ and PDGFR $\beta$ expression in non-irradiated bulk NSCLC cells, radiation survived adherent cells, nonirradiated sphere cells and radiation survived sphere cells (Figure 6). An increase of expression of CXCR4, in non-irradiated sphere cells and radiation survived sphere cells, was observed (Figure 6A,B). PDGFR $\alpha$ was not detectable in any of the four cell populations investigated (data not shown). PDGFR beta was also undetectable in non-irradiated $\mathrm{H} 460$ and A549 cells and non-irradiated lung tumor sphere cells. In contrast, radiation survived cells, adherent cells and sphere cells, in both cell lines showed a significant increase of PDGFR beta expression (Figure 6C). 

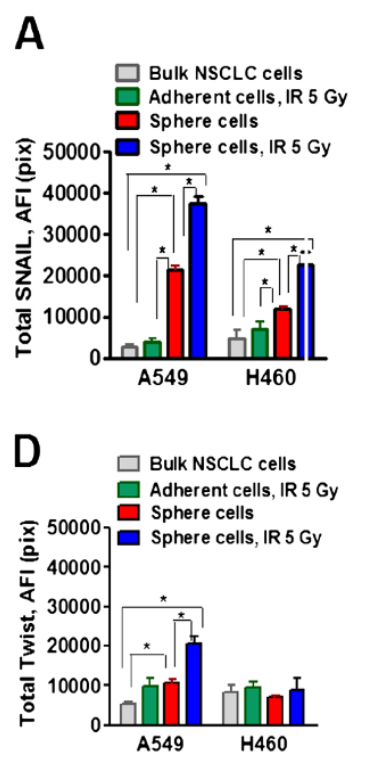

B

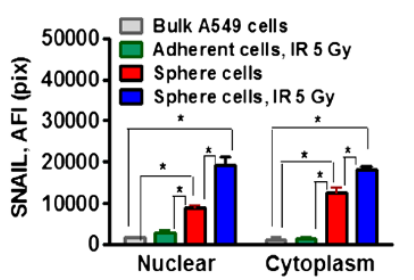

E

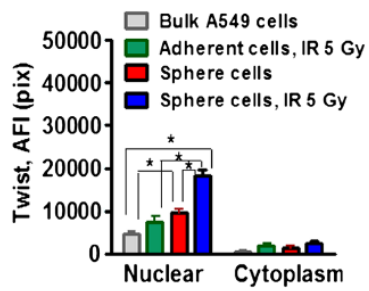

C

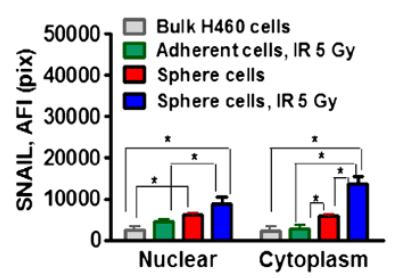

$\mathbf{F}$

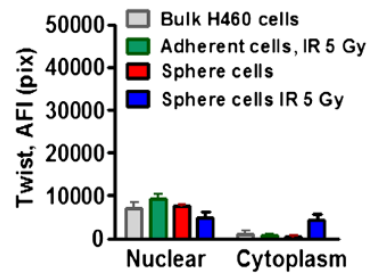

Figure 3 Upregulation of EMT-associated transcription factors Snail1 and Twist in radiation survived sphere cells. Non-irradiated NSCLC cells, radiation survived adherent cells, non-irradiated sphere cells and radiation survived sphere cells were collected and seeded into collagen precoated 96-well plates. 8 hours later, the cells were fixed, permeabilazed and immunofluorescently stained for Snail1 and Twist. The cell nuclei were stained with Hoechst33342. Cell images were acquired using the Cellomics ArrayScan HCS Reader (40X objective) and analyzed using the Compartment Analysis BioApplication Software Module. Fluorescence intensities of respective lgG controls were subtracted. Each point presents average intensities (pixels) estimated for 3000 cells. (A-C) Analysis of Snail1 expression. The total average fluorescence intensities of Snail1 (A) in the non-irradiated NSCLC cells (grey), in the radiation survived adherent cells (green), in the non-irradiated sphere cells (red) and in the radiation survived sphere cells (blue) are presented. (B,C) Snail1 distributions, in the nuclei and cytoplasm compartments of the same cell populations, are shown. (D-F) Analysis of Twist expression. The total average fluorescence intensities of Twist (D) in the non-irradiated NSCLC cells (grey), in the radiation survived adherent cells (green), in the non-irradiated sphere cells (red) and in the radiation survived sphere cells (blue) are presented. $(\mathbf{E}, \mathbf{F})$ Twist distributions, in the nuclei and cytoplasm compartments of the same cell populations, are shown.

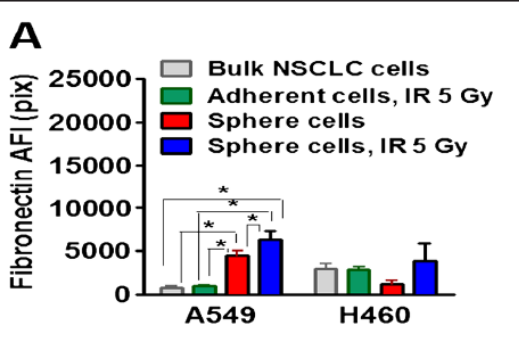

C

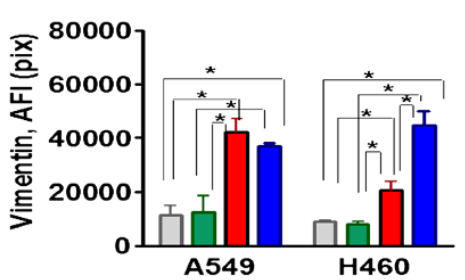

B

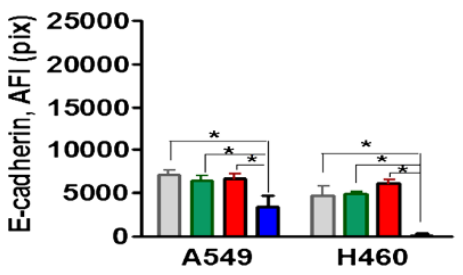

D

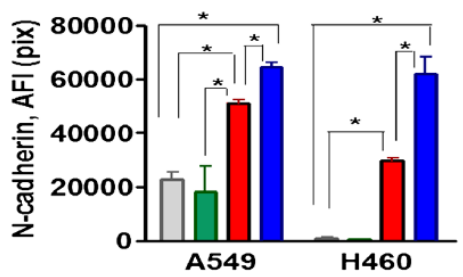

Figure 4 The radiation survived lung tumor sphere cells show upregulation of EMT markers. Non-irradiated A549 and H460 cells, radiation survived adherent cells, non-irradiated sphere cells and radiation survived sphere cells were collected and seeded into collagen precoated 96-well plates. Eight hours later, cells were stained for fibronectin, vimentin, N-cadherin and E-cadherin. The cell nuclei were stained with Hoechst33342. Cell images were acquired using the Cellomics ArrayScan HCS Reader (40X objective) and analyzed using the Target Activation BioApplication Software Module. The total average fluorescence intensities of fibronectin (A), E-cadherin (B), vimentin (C), and N-cadherin (D), in the non-irradiated bulk NSCLC cells (grey), in the radiation survived adherent cells (green), in the non-irradiated sphere cells (red) and in the radiation survived sphere cells (blue) are presented. Fluorescence intensities of the respective lgG controls were subtracted. Each point presents average intensities (pixels) estimated for 3000 cells. 

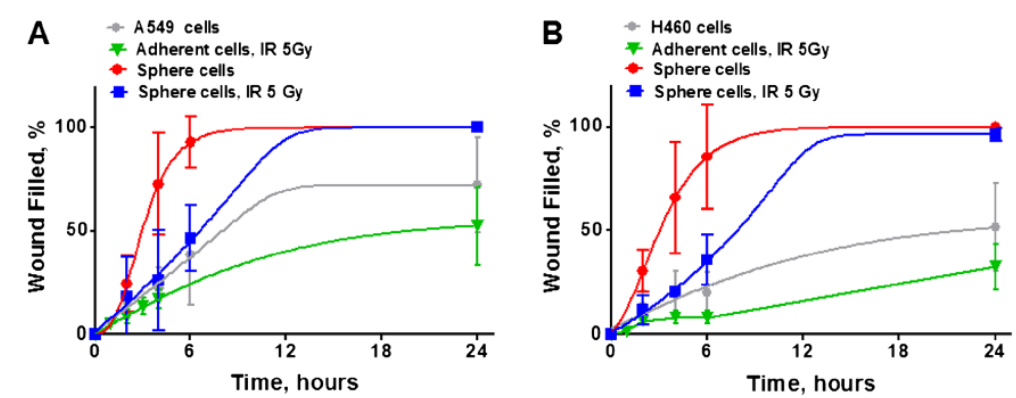

Figure 5 Wound healing assay demonstrates high migratory potential of the radiation survived sphere cells. Non-irradiated NSCLC cells, radiation survived adherent cells, non-irradiated sphere cells and radiation survived sphere cells were collected and grown to monolayers in 6-well plates. Then cells were scratched and incubated for 0-24 hours. (A,B) The migratory rates of the bulk NSCLC cells (grey), of the radiation survived adherent cells (green), of the non-irradiated sphere cells (red) and of the radiation survived sphere cells (blue) in a wounding assay, were determined by measuring wound width as a function of time. Data are expressed as the mean \pm SD of three experiments.

\section{The effect of PDGFR inhibition}

To test whether PDGFR beta inhibition will potentiate the effect of IR treatment on NSCLC cells we used axitinib and dasatinib, the tyrosine kinase inhibitors with anti-PDGFR beta activity, in clonogenic survival assay.
The results of the clonogenic survival assay presented in Figure 7 and Table 1 demonstrate that combining IR treatment with PDGFR inhibition increases the antitumor effect of ionizing radiation. A significant reduction of the proliferating fraction of the NSCLC cells was determined
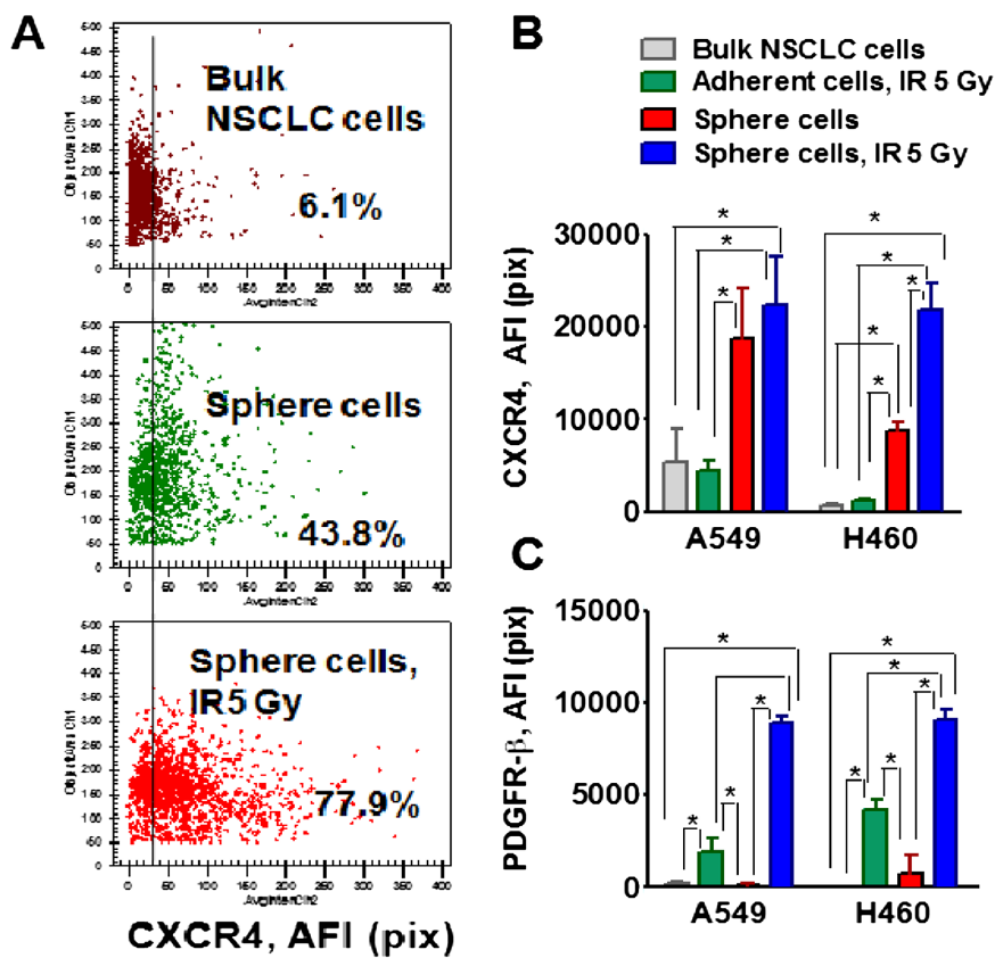

Figure 6 Radiation- survived sphere cells display upregulation of CXCR4 and PDGFR-beta receptors. Bulk NSCLC cells, radiation survived adherent cells, non-irradiated sphere cells from the third generation, and radiation survived sphere cells were seeded into collagen precoated 96-well plates for 8 hours. The cells were fixed and immunofluorescently stained for CXCR4 and PDGFR-beta. The cell nuclei were stained with Hoechst33342. Cell images were acquired using the Cellomics ArrayScan HCS Reader (40x objective) and analyzed using the Target Activation BioApplication Software Module. (A) Fluorescence intensity of CXCR4 in non-irradiated A549 cells (brown), non-irradiated sphere cells (green), and radiation survived sphere cells (red) plotted against the object area. Each spot represents a single cell. Cells to the right of the black line are positive (above lgG control staining). $(\mathbf{B}, \mathbf{C})$ The total average fluorescence intensities of CXCR4 (B) and PDGFR-beta (C), in non-irradiated bulk NSCLC cells (grey), in the radiation survived adherent cells (green), in the non-irradiated sphere cells (red) and in the radiation survived sphere cells (blue) are shown. Fluorescence intensities of respective lgG controls were subtracted. Each point presents average intensities (pixels) estimated for 3000 cells. 

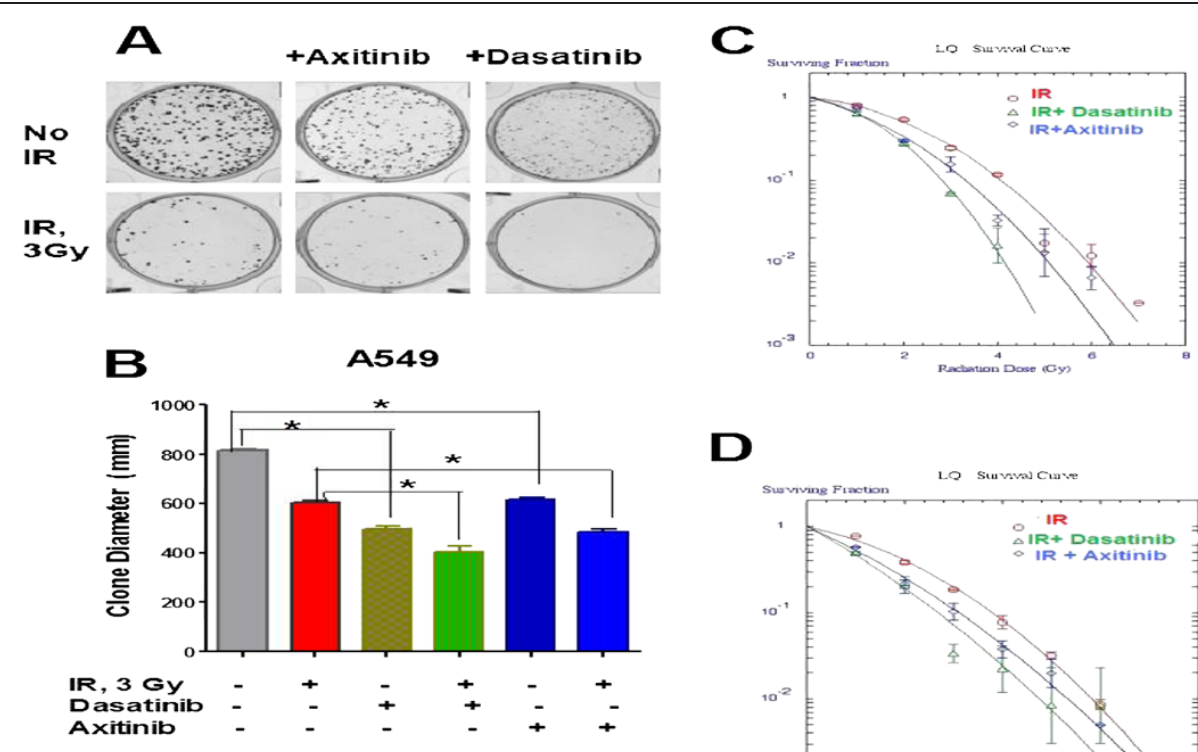

$\mathbf{D}$

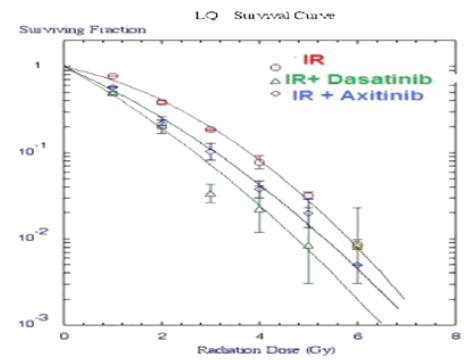

Figure 7 Clonogenic analysis of cells treated with PDGFR inhibitors and IR. Cells were suspended, counted, irradiated (0-10 Gy) and plated. The next day, axitinib or dasatinib were added or not into the culture media. Then culture media with inhibitors was changed every day. Cells were fixed and clonogenic survival was estimated on the seventh day after IR treatment. (A) Representative images of A549 cell clones generated from IR (3Gy) treated or non-treated cells and growing in presence/absence of axitinib or dasatinib. (B) Comparison of clone sizes grown from A549 cells irradiated (3 Gy) or non-irradiated and growing in presence/absence of axitinib or dasatinib. (C,D) Radiation survival curves show radiation sensitivity of $\mathrm{A} 549$ (C) and $\mathrm{H} 460$ (D) cells growing without inhibitors (red line), growing in the presence of axitinib (1 $\mu \mathrm{M}$, blue line) or dasatinib (1 $\mu \mathrm{M}$, green line). Average data of 5 experiments are presented.

if irradiated cells were grown in the presence of inhibitors. However, the treatment of irradiated cells with dasatinib resulted in the biggest reduction of clonogenic survival in the both cell lines.

\section{Discussion}

In the present study, we demonstrate that NSCLC cells that survived ionizing radiation treatment have a complex phenotype which includes all of the properties of CSCs and markers of EMT. Evidence has recently been accumulating to support the hypothesis that tumors contain a small population of CSCs, also known as tumor initiating cells, which exhibit stem-like cell properties including selfrenewal, tumor sphere formation, differentiation and tumor formation in a xenotransplant model $[9,47]$.
CD166/ALCAM is a 100-105 kD type I transmembrane glycoprotein member of the immunoglobulin superfamily of proteins [48], which has also recently been reported as a CSC marker in colorectal and lung cancers [20,49]. Our finding that CD166/ALCAM expression is increased in non-irradiated A549 and H460 lung sphere cells and even more dramatically upregulated in radiation survived sphere cells of the A549 cell line suggests that CD166/ ALCAM might serve as a marker for the detection of CSCs and radioresistant counterparts within NSCLC tumors and bears the potential to predict the outcome of radiotherapy by assessment of CSC density. We demonstrate here that the elevated level of CXCR4 expression could also be considered as a marker for non-irradiated human lung sphere cells and also for radiation survived

Table 1 Comparison of radiosensitivity of NSCLC cells treated with RTK inhibitors

\begin{tabular}{|c|c|c|c|c|c|c|}
\hline \multirow{2}{*}{$\begin{array}{l}\text { Cell line } \\
\text { Treatment }\end{array}$} & \multicolumn{3}{|c|}{ A549 } & \multicolumn{3}{|c|}{$\mathrm{H} 460$} \\
\hline & IR & IR + Dasatinib & IR + Axitinib & IR & IR + Dasatinib & IR cp Axitinib \\
\hline$D_{0}$ & $1.058 \pm 0.07$ & $0.920 \pm 0.05$ & $1.015 \pm 0.03$ & $1.077 \pm 0.11$ & $0.914 \pm 0.11$ & $1.047 \pm 0.12$ \\
\hline $\boldsymbol{p}(\mathrm{VS} \mathbb{R})$ & - & 0.006 & 0.149 & - & 0.009 & 0.406 \\
\hline$\tilde{n}$ & $2.773 \pm 0.43$ & $1.464 \pm 0.30$ & $1.892 \pm 0.22$ & $4.454 \pm 1.72$ & $2.206 \pm 1.13$ & $2.630 \pm 0.61$ \\
\hline $\boldsymbol{p}(\mathrm{VS} \mid \mathrm{R})$ & - & $<0.0001$ & 0.027 & - & 0.011 & 0.029 \\
\hline
\end{tabular}

Results were calculated with linear quadratic and single hit multi-target models and presented as $D_{0}-G y$, the dose required to reduce the fraction of survived cells to $37 \%$ and $\tilde{n}$ (extrapolation number derived by extension of the linear proportion of the radiation survival curve to the ordinate of the graph using a log/linear plot). 
sphere cells. Previously, the upregulation of CXCR4, a receptor of stromal derived factor (SDF/ CXCL12), has been reported as functionally crucial for the maintenance of stemness in drug-resistant NSCLC cells [13,45].

CD44, a receptor for hyaluronic acid and a well known stem cell marker in many epithelial cancers, is a cell-surface glycoprotein involved in cell-cell interactions, cell adhesion and migration [50,51]. CD44 can also interact with other ligands including growth factor receptors such as EGFR2 and PDGFR, osteopontin, collagens and matrix metalloproteinases (MMPs) which are involved in tumor progression and metastasis [52]. CD44 gene transcription is, at least in part, activated by betacatenin and Wnt signaling [53]. A recent study discovered $\mathrm{CD} 44$ as a marker which significantly correlates with response to radiotherapy in early stage larynx cancer patients, both at the mRNA and protein levels [54].

As both CD44 and nuclear beta- catenin are dramatically upregulated in radiation survived lung cells, we hypothesize that CD44/beta-catenin expression might serve as another predictive marker for recurrence after NSCLC radiation therapy.

Oct-4 and Sox-2 are stem cell transcription factors [55]. Our finding that Oct- 4 and Sox- 2 are highly upregulated in radiation survived sphere cells from the A549 cell line and highly upregulated in radiation surviving adherent H460 cells, in comparison to respective naïve lung adherent NSCLC cells and sphere cells, is suggesting that radiation treatment may select for aggressive tumorigenic phenotype, and that this selection is cell line specific. Recently, it was reported that ionizing radiation induced a breast CSC phenotype in non-stem cell populations. This transition was Notch-dependent and coincided with upregulation of Oct-4 [56].

EMT can be a player in cancer initiation, promoting the clonal expansion of premalignant epithelial cells [57]. Cancer cells undergoing EMT acquire the capacity to migrate, invade the stroma and metastasize. During metastasis, the EMT program enables these cancer cells to propagate from a primary tumor and also supports progression from micro- to macro-metastases $[58,59]$. We found that radiation survived sphere cells also show upregulation of the signal transducer CD24, whereas non-irradiated sphere cells display very low levels of CD24. It is conceivable that CD24 upregulation is discriminating the EMT phenotype in radiation survived cells. In many tumor types, CD24 expression is associated with metastasis [60]. Recently, CD24+ ovarian cancer cells exhibiting EMT phenotype were reported [61]. EMT is an embryonic process leading to loss of cell-cell contact, repression of E-cadherin expression and increased cell motility. EMT transition in epithelial cells leads to switching from E-cadherin to N-cadherin [31]. In cancers, EMT is also associated with resistance to chemotherapeutic drugs and radiation [27,28], and epithelial tumor cells undergoing EMT may develop CSC traits $[29,30]$.

Our observation is that lung sphere cells, non-irradiated and radiation survived cells, have higher motility in comparison to adherent non-irradiated and radiation survived NSCLC cells, as detected by a wound healing assay in vitro, as well as upregulation of EMT associated markers in radiation survived lung sphere cells, which clearly indicates that radiation survived sphere cells have a very complex phenotype combining both human lung CSC and EMT characteristics.

Radiation survived sphere cells demonstrated downregulation of E-cadherin and upregulation of $\mathrm{N}$-cadherin, fibronectin and vimentin in comparison with parental A549 and H460 cells thus confirming EMT activation in the cells. The E-cadherin promoter is repressed directly or indirectly by specific developmental transcription factors such as Twist1 and Snail1, disrupts the polarity of epithelial cells and maintains a mesenchymal phenotype $[59,62]$. Interestingly, N-cadherin, vimentin and Snail1 upregulation were also observed in the non-irradiated sphere cells, however, the levels of these proteins were significantly higher in the radiation survived sphere cells. Snail 1 is a zinc-finger transcription factor belonging to the Snail super family and it is characterized by a strongly conserved carboxy-terminal region containing four to six C2H2-zinc fingers. Snail1 acts as a transcriptional repressor, when the fingers bind to E-box motifs (5'-CANNTG-3') in target promoters, including the E-cadherin gene $(C D H 1)$ promoter. Snail is a critical transcriptional repressor of E-cadherin and its expression induces EMT $[29,63]$. Snail upregulation is associated with radioresistance and chemoresistance in epithelial tumors $[64,65]$. Twist is a basic helix-loop-helix (bHLH) transcription factor, which plays critical roles throughout development, including influencing mesoderm formation, neurogenesis, myogenesis and neural crest cell migration and differentiation [66]. A number of reports have implicated Twist1 in oncogenesis through its ability to inhibit DNA damage-induced apoptosis and promote metastasis through the induction of EMT [67]. Increased Twist1 expression is correlated with the increased risk of metastasis and poor prognosis in a number of solid tumor types including breast, prostate, ovarian and lung $[68,69]$.

The radiation survived sphere cells originated from both A549 and H460 cell lines expressed a high level of Snail1, whereas Twist upregulation was observed only in radiation survived cells that originated from the A549 cell line. This finding suggests differential levels of EMT activation in radiation survived cells and that the radiation survived sphere cells originating from the A549 cell line have a more advanced EMT phenotype. This suggestion is in concordance with the reports that Snail1 
plays an important role in inducing the first EMT steps that lead to the initiation of the invasive process, whereas Twist 1 has a critical role in the development of distant metastases by prompting breast cancer cells to enter the bloodstream [63,70]. A combination of EMT and stem cell-like phenotypes is an important predictor of aggressive biologic behavior and has an independent prognostic value in predicting the outcome of primary gastric cancer [71]. However, additional studies are necessary to clarify the impact of these cell subpopulations in NSCLC radiation resistance.

Platelet derived growth factor (PDGF) and its receptors play an important role in tumor cell migration and vasculature formation, and these molecules are also well known drivers of mesenchymal cell proliferation [72,73]. We revealed that PDGFR- beta was undetectable in non treated parental cells and non-irradiated lung sphere cells; however it was highly expressed in radiation survived sphere cells and adherent radiation survived cells. PDFGR- beta is a receptor tyrosine kinase (RTK) whose downstream signaling is effectively abrogated by second generation RTK inhibitors, such as Axitinib (AG013736) [74] and dasatinib [75,76]. Using a classical clonogenic assay for testing the effect of ionizing radiation, axitinib, dasatinib and the combination of IR with axitinib or dasatinib treatment, we observed that RDGFR signaling may be important for NSCLC radiation resistance as the combination of IR with dasatinib or axitinib treatment significantly increases the efficacy of IR treatment in NSCLC cells. However, combining IR with dasatinib exerts a more profound effect than the combination of IR with axitinib.

In conclusion, the present study demonstrates that NSCLC cells that survived IR treatment and propagated as tumor spheres have a complex phenotype which includes $\mathrm{f}$ the properties of CSCs. They have a significant upregulation of CD166, CXCR4, CD44, nuclear betacatenin, Oct-4, and/or Sox-2 expression and they acquire motility. Radiation survived cells also show an EMT phenotype, including a reduction of E-cadherin and an upregulation of $\mathrm{N}$-cadherin and vimentin. These cells also demonstrate an upregulation of Snail1, a major transcription factor involved in EMT activation and promotion.

PDGFR-beta signaling, which is specifically upregulated in radiation survived sphere cells and IR-treated adherent cells, could be considered as prognostic markers for NSCLC radiation therapy and they may also serve as the targets for improving the efficacy of NSCLC therapy.

Further in vivo studies of radiation survived cells may provide key information on relevant pathways to be targeted to increase the radiation response in NSCLC.

\section{Competing interests}

The authors declare that they have no competing interest.

\section{Authors' contribution}

$V L$ and $M G$ conceived the idea; RG, CB, LB, PB and ME performed the experiments; $R G, M E$ and $V L$ designed the experiments and analyzed the data. $V L$ wrote the manuscript. All authors read and approved the manuscript.

\section{Acknowledgements}

We would like to thank Simul Parikh for the help with cell culture; and Brian Nolen and Dianna Pappert Fennell for the helpful assistance with this manuscript.

This work is supported by the grants: The Pittsburgh Foundation M2010$0021(\mathrm{VL})$ and NIH 1R21CA164740-01 (VL). This project used the Flow Cytometry facility that is supported in part by award P30CA047904.

\section{Author details}

'University of Pittsburgh Cancer Institute, Pittsburgh, PA 15213, USA. ${ }^{2}$ Department of Medicine, Pittsburg, PA 15213, USA. ${ }^{3}$ Departments of Pathology, University of Pittsburgh, Pittsburgh, PA 15213, USA. ${ }^{4}$ University of Pittsburgh Cancer Institute, Hillman Cancer Center, Rm. 1.19c, 5117 Center Ave, Pittsburgh, PA 15213, USA.

Received: 3 April 2013 Accepted: 14 August 2013

Published: 16 August 2013

\section{References}

1. Siegel R, Naishadham D, Jemal A: Cancer statistics, 2012. CA Cancer J Clin 2012, 62(1):10-29.

2. Parsons A, Daley A, Begh R, Aveyard P: Influence of smoking cessation after diagnosis of early stage lung cancer on prognosis: systematic review of observational studies with meta-analysis. BMJ 2010, 340:b5569.

3. Greco FA, Stroup SL, Gray JR, Hainsworth JD: Paclitaxel in combination chemotherapy with radiotherapy in patients with unresectable stage III non-small-cell lung cancer. J Clin Oncol 1996, 14(5):1642-1648.

4. Danesi R, Pasqualetti G, Giovannetti E, Crea F, Altavilla G, Del Tacca M, Rosell $\mathrm{R}$ : Pharmacogenomics in non-small-cell lung cancer chemotherapy. Advanced drug delivery reviews 2009, 61(5):408-417.

5. Reya T, Morrison SJ, Clarke MF, Weissman IL: Stem cells, cancer, and cancer stem cells. Nat Geosci 2001, 414(6859):105-111.

6. Reya T, Clevers H: Wnt signalling in stem cells and cancer. Nat Geosci 2005, 434(7035):843-850

7. Clarke MF, Fuller M: Stem cells and cancer: two faces of eve. Cell 2006, 124(6):1111-1115.

8. Al-Hajj M, Wicha MS, Benito-Hernandez A, Morrison SJ, Clarke MF: Prospective identification of tumorigenic breast cancer cells. Proc Natl Acad Sci U S A 2003, 100(7):3983-3988.

9. Dontu G, Abdallah WM, Foley JM, Jackson KW, Clarke MF, Kawamura MJ, Wicha MS: In vitro propagation and transcriptional profiling of human mammary stem/progenitor cells. Genes Dev 2003, 17(10):1253-1270.

10. Hermann PC, Huber SL, Herrler T, Aicher A, Ellwart JW, Guba M, Bruns CJ, Heeschen C: Distinct populations of cancer stem cells determine tumor growth and metastatic activity in human pancreatic cancer. Cell Stem Cell 2007, 1(3):313-323.

11. Ignatova TN, Kukekov VG, Laywell ED, Suslov ON, Vrionis FD, Steindler DA: Human cortical glial tumors contain neural stem-like cells expressing astroglial and neuronal markers in vitro. Glia 2002, 39(3):193-206.

12. Eramo A, Lotti F, Sette G, Pilozzi E, Biffoni M, Di Virgilio A, Conticello C, Ruco L, Peschle C, De Maria R: Identification and expansion of the tumorigenic lung cancer stem cell population. Cell Death Differ 2008, 15(3):504-514.

13. Levina V, Marrangoni AM, DeMarco R, Gorelik E, Lokshin AE: Drug-selected human lung cancer stem cells: cytokine network, tumorigenic and metastatic properties. PLOS ONE 2008, 3(8):e3077.

14. Gorelik E, Lokshin A, Levina V: Lung cancer stem cells as a target for therapy. Anticancer Agents Med Chem 2010, 10(2):164-171.

15. McDermott SP, Wicha MS: Targeting breast cancer stem cells. Mol Oncol 2010, 4(5):404-419.

16. Dean M, Fojo T, Bates S: Tumour stem cells and drug resistance. Nat Rev Cancer 2005, 5(4):275-284.

17. Bertolini G, Roz L, Perego P, Tortoreto M, Fontanella E, Gatti L, Pratesi G, Fabbri A, Andriani F, Tinelli S, et al: Highly tumorigenic lung cancer CD133+ cells display stem-like features and are spared by cisplatin treatment. Proc Natl Acad Sci U S A 2009, 106(38):16281-16286. 
18. Jiang F, Qiu Q, Khanna A, Todd NW, Deepak J, Xing L, Wang H, Liu Z, Su Y, Stass SA, et al: Aldehyde dehydrogenase 1 is a tumor stem cellassociated marker in lung cancer. Mol Cancer Res 2009, 7(3):330-338.

19. Levina V, Marrangoni A, Wang T, Parikh S, Su Y, Herberman R, Lokshin A, Gorelik E: Elimination of human lung cancer stem cells through targeting of the stem cell factor-c-kit autocrine signaling loop. Cancer Res 2010, 70(1):338-346

20. Zhang WC, Shyh-Chang N, Yang H, Rai A, Umashankar S, Ma S, Soh BS, Sun $L L$, Tai BC, Nga ME, et al: Glycine decarboxylase activity drives non-small cell lung cancer tumor-initiating cells and tumorigenesis. Cell 2012, 148(1-2):259-272.

21. Ho MM, Ng AV, Lam S, Hung JY: Side population in human lung cancer cell lines and tumors is enriched with stem-like cancer cells. Cancer Res 2007, 67(10):4827-4833.

22. Singh S, Trevino J, Bora-Singhal N, Coppola D, Haura E, Altiok S, Chellappan SP: EGFR/Src/Akt signaling modulates Sox2 expression and self-renewal of stem-like side-population cells in non-small cell lung cancer. Molecular cancer 2012, 11:73.

23. Chen YC, Hsu HS, Chen YW, Tsai TH, How CK, Wang CY, Hung SC, Chang YL, Tsai $M L$, Lee $Y$, et al: Oct- 4 expression maintained cancer stem-like properties in lung cancer-derived CD133-positive cells. PLOS ONE 2008, 3(7):e2637.

24. Giangreco A, Lu L, Vickers C, Teixeira VH, Groot KR, Butler CR, llieva EV, George PJ, Nicholson AG, Sage EK, et al: beta-catenin determines upper airway progenitor cell fate and preinvasive squamous lung cancer progression by modulating epithelial-mesenchymal transition. J Pathol 2012, 226(4):575-587.

25. Teng $Y$, Wang $X$, Wang $Y$, Ma D: Wnt/beta-catenin signaling regulates cancer stem cells in lung cancer A549 cells. Biochem Biophys Res Commun 2010, 392(3):373-379.

26. Shien K, Toyooka S, Ichimura K, Soh J, Furukawa M, Maki Y, Muraoka T, Tanaka N, Ueno T, Asano H, et al: Prognostic impact of cancer stem cellrelated markers in non-small cell lung cancer patients treated with induction chemoradiotherapy. Lung Cancer 2012, 77(1):162-167.

27. Singh A, Settleman J: EMT, cancer stem cells and drug resistance: an emerging axis of evil in the war on cancer. Oncogene 2010, 29(34):4741-4751.

28. Kong D, Li Y, Wang Z, Sarkar FH: Cancer stem cells and epithelial-to -mesenchymal transition (EMT)-phenotypic cells: are they cousins or twins? Cancers (Basel) 2011, 3(1):716-729.

29. Mani SA, Guo W, Liao MJ, Eaton EN, Ayyanan A, Zhou AY, Brooks M, Reinhard F, Zhang CC, Shipitsin M, et al: The epithelial-mesenchymal transition generates cells with properties of stem cells. Cell 2008, 133(4):704-715.

30. Scheel C, Weinberg RA: Cancer stem cells and epithelial-mesenchymal transition: concepts and molecular links. Semin Cancer Biol 2012, 22(5-6):396-403.

31. Wijnhoven BP, Dinjens WN, Pignatelli M: E-cadherin-catenin cell-cell adhesion complex and human cancer. The British journal of surgery 2000, 87(8):992-1005.

32. Scheel C, Eaton EN, Li SH, Chaffer CL, Reinhardt F, Kah KJ, Bell G, Guo W, Rubin J, Richardson AL, et al: Paracrine and autocrine signals induce and maintain mesenchymal and stem cell states in the breast. Cell 2011, 145(6):926-940.

33. Polyak K, Weinberg RA: Transitions between epithelial and mesenchymal states: acquisition of malignant and stem cell traits. Nat Rev Cancer 2009, 9(4):265-273.

34. Craene BD, Berx G: Regulatory networks defining EMT during cancer initiation and progression. Nat Rev Cancer 2012, 13(2):97-110.

35. Heddleston JM, Li Z, MCLendon RE, Hjelmeland AB, Rich JN: The hypoxic microenvironment maintains glioblastoma stem cells and promotes reprogramming towards a cancer stem cell phenotype. Cell Cycle 2009, 8(20):3274-3284

36. Salnikov AV, Liu L, Platen M, Gladkich J, Salnikova O, Ryschich E, Mattern J, Moldenhauer G, Werner J, Schemmer P, et al: Hypoxia induces EMT in low and highly aggressive pancreatic tumor cells but only cells with cancer stem cell characteristics acquire pronounced migratory potential. PLOS One 2012, 7(9):e46391.

37. Andarawewa KL, Erickson AC, Chou WS, Costes SV, Gascard P, Mott JD, Bissell MJ, Barcellos-Hoff $\mathrm{MH}$ : lonizing radiation predisposes nonmalignant human mammary epithelial cells to undergo transforming growth factor beta induced epithelial to mesenchymal transition. Cancer Res 2007, 67(18):8662-8670.
38. Jung JW, Hwang SY, Hwang JS, Oh ES, Park S, Han IO: lonising radiation induces changes associated with epithelial-mesenchymal transdifferentiation and increased cell motility of A549 lung epithelia cells. Eur J Cancer 2007, 43(7):1214-1224.

39. Zhou P, Du LF, Lv GQ, Yu XM, Gu YL, Li JP, Zhang C: Functional polymorphisms in CD166/ALCAM gene associated with increased risk for breast cancer in a Chinese population. Breast Cancer Res Treat 2011, 128(2):527-534.

40. Kawamoto A, Yokoe T, Tanaka K, Saigusa S, Toiyama Y, Yasuda H, Inoue Y, Miki C, Kusunoki M: Radiation induces epithelial-mesenchymal transition in colorectal cancer cells. Oncol Rep 2012, 27(1):51-57.

41. Kim H, Yoo SB, Sun P, Jin Y, Jheon S, Lee CT, Chung JH: Alteration of the Ecadherin/beta-catenin complex is an independent poor prognostic factor in lung adenocarcinoma. Korean journal of pathology 2013, 47(1):44-51.

42. Hall EJ: Radiation dose-rate: a factor of importance in radiobiology and radiotherapy. The British journal of radiology 1972, 45(530):81-97.

43. Denker SP, Barber DL: Cell migration requires both ion translocation and cytoskeletal anchoring by the Na-H exchanger NHE1. The Journal of cell biology 2002, 159(6):1087-1096.

44. Levina V, Marrangoni AM, Demarco R, Gorelik E, Lokshin AE: Multiple effects of TRAIL in human carcinoma cells: Induction of apoptosis, senescence, proliferation, and cytokine production. Exp Cell Res 2008, 314(7):1605-1616.

45. Jung MJ, Rho JK, Kim YM, Jung JE, Jin YB, Ko YG, Lee JS, Lee SJ, Lee JC, Park MJ: Upregulation of CXCR4 is functionally crucial for maintenance of stemness in drug-resistant non-small cell lung cancer cells. Oncogene 2013, 32(2):209-221.

46. Ball SG, Shuttleworth A, Kielty CM: Inhibition of platelet-derived growth factor receptor signaling regulates Oct4 and Nanog expression, cell shape, and mesenchymal stem cell potency. Stem Cells 2012, 30(3):548-560.

47. Gupta PB, Chaffer $C L$, Weinberg RA: Cancer stem cells: mirage or reality? Nat Med 2009, 15(9):1010-1012

48. Ofori-Acquah SF, King JA: Activated leukocyte cell adhesion molecule: a new paradox in cancer. Translational research: the journal of laboratory and clinical medicine 2008, 151(3):122-128.

49. Lugli A, lezzi G, Hostettler I, Muraro MG, Mele V, Tornillo L, Carafa V, Spagnoli G, Terracciano L, Zlobec I: Prognostic impact of the expression of putative cancer stem cell markers CD133, CD166, CD44s, EpCAM, and ALDH1 in colorectal cancer. Br J Cancer 2010, 103(3):382-390.

50. Haynes BF, Liao HX, Patton KL: The transmembrane hyaluronate receptor (CD44): multiple functions, multiple forms. Cancer Cells 1991, 3(9):347-350.

51. Zoller M: CD44: can a cancer-initiating cell profit from an abundantly expressed molecule? Nat Rev Cancer 2011, 11(4):254-267.

52. Misra S, Heldin P, Hascall VC, Karamanos NK, Skandalis SS, Markwald RR, Ghatak S: Hyaluronan-CD44 interactions as potential targets for cancer therapy. The FEBS journal 2011, 278(9):1429-1443.

53. Katoh M: WNT signaling in stem cell biology and regenerative medicine. Curr Drug Targets 2008, 9(7):565-570.

54. de Jong MC, Pramana J, van der Wal JE, Lacko M, Peutz-Kootstra CJ, de Jong JM, Takes RP, Kaanders JH, van der Laan BF, Wachters J, et al: CD44 expression predicts local recurrence after radiotherapy in larynx cancer. Clin Cancer Res 2010, 16(21):5329-5338.

55. Calloni R, Cordero EA, Henriques JA, Bonatto D: Reviewing and updating the major molecular markers for stem cells. Stem Cells Dev 2013, 22(9):1455-1476.

56. Lagadec C, Vlashi E, Della Donna L, Dekmezian C, Pajonk F: Radiation-induced reprogramming of breast cancer cells. Stem Cells 2012, 30(5):833-844.

57. Tellez CS, Juri DE, Do K, Bernauer AM, Thomas CL, Damiani LA, Tessema M, Leng S, Belinsky SA: EMT and stem cell-like properties associated with miR-205 and miR-200 epigenetic silencing are early manifestations during carcinogen-induced transformation of human lung epithelial cells. Cancer Res 2011, 71(8):3087-3097.

58. Ouyang G, Wang Z, Fang X, Liu J, Yang CJ: Molecular signaling of the epithelial to mesenchymal transition in generating and maintaining cancer stem cells. Cell Mol Life Sci 2010, 67(15):2605-2618.

59. Thiery JP, Lim CT: Tumor dissemination: an EMT affair. Cancer Cell 2013, 23(3):272-273

60. Lee HJ, Choe G, Jheon S, Sung SW, Lee CT, Chung JH: CD24, a novel cancer biomarker, predicting disease-free survival of non-small cell lung carcinomas: a retrospective study of prognostic factor analysis from the viewpoint of forthcoming (seventh) new TNM classification. J Thorac Oncol 2010, 5(5):649-657. 
61. Kang KS, Choi YP, Gao MQ, Kang S, Kim BG, Lee JH, Kwon MJ, Shin YK, Cho $\mathrm{NH}: \mathrm{CD} 24(+)$ ovary cancer cells exhibit an invasive mesenchymal phenotype. Biochem Biophys Res Commun 2013, 432(2):333-338.

62. Yang J, Weinberg RA: Epithelial-mesenchymal transition: at the crossroads of development and tumor metastasis. Developmental cell 2008, 14(6):818-829.

63. Onder TT, Gupta PB, Mani SA, Yang J, Lander ES, Weinberg RA: Loss of E-cadherin promotes metastasis via multiple downstream transcriptional pathways. Cancer Res 2008, 68(10):3645-3654.

64. Hung JJ, Yang MH, Hsu HS, Hsu WH, Liu JS, Wu KJ: Prognostic significance of hypoxia-inducible factor-1alpha, TWIST1 and Snail expression in resectable non-small cell lung cancer. Thorax 2009, 64(12):1082-1089.

65. Martin A, Cano A: Tumorigenesis: twist1 links EMT to self-renewal. Nature cell biology 2010, 12(10):924-925.

66. Barnes RM, Firulli AB: A twist of insight - the role of twist-family bHLH factors in development. The International journal of developmental biology 2009, 53(7):909-924.

67. Zhuo WL, Wang Y, Zhuo XL, Zhang YS, Chen ZT: Short interfering RNA directed against TWIST, a novel zinc finger transcription factor, increases A549 cell sensitivity to cisplatin via MAPK/mitochondrial pathway. Biochem Biophys Res Commun 2008, 369(4):1098-1102.

68. Ansieau S, Morel AP, Hinkal G, Bastid J, Puisieux A: TWISTing an embryonic transcription factor into an oncoprotein. Oncogene 2010, 29(22):3173-3184.

69. Pallier K, Cessot A, Cote JF, Just PA, Cazes A, Fabre E, Danel C, Riquet M, Devouassoux-Shisheboran M, Ansieau S, et al: TWIST1 a new determinant of epithelial to mesenchymal transition in EGFR mutated lung adenocarcinoma. PLoS One 2012, 7(1):e29954.

70. Yang J, Mani SA, Donaher JL, Ramaswamy S, Itzykson RA, Come C, Savagner P, Gitelman I, Richardson A, Weinberg RA: Twist, a master regulator of morphogenesis, plays an essential role in tumor metastasis. Cell 2004, 117(7):927-939.

71. Ryu HS, Park Do J, Kim HH, Kim WH, Lee HS: Combination of epithelialmesenchymal transition and cancer stem cell-like phenotypes has independent prognostic value in gastric cancer. Hum Pathol 2012, 4(4):520-528.

72. Cool J, DeFalco TJ, Capel B: Vascular-mesenchymal cross-talk through Vegf and Pdgf drives organ patterning. Proc Natl Acad Sci U S A 2011, 108(1):167-172

73. Yokoyama Y, Mori S, Hamada Y, Hieda M, Kawaguchi N, Shaker M, Tao Y, Yoshidome K, Tsujimoto M, Matsuura N: Platelet-derived growth factor regulates breast cancer progression via beta-catenin expression. Pathobiology: journal of immunopathology, molecular and cellular biology 2011, 78(5):253-260.

74. Ellis PM, Al-Saleh K: Multitargeted anti-angiogenic agents and NSCLC: clinical update and future directions. Crit Rev Oncol Hematol 2012, 84(1):47-58

75. Gnoni A, Marech I, Silvestris N, Vacca A, Lorusso V: Dasatinib: an antitumour agent via Src inhibition. Curr Drug Targets 2011, 12(4):563-578.

76. Montero JC, Seoane S, Ocana A, Pandiella A: Inhibition of SRC family kinases and receptor tyrosine kinases by dasatinib: possible combinations in solid tumors. Clin Cancer Res 2011, 17(17):5546-5552.

doi:10.1186/1476-4598-12-94

Cite this article as: Gomez-Casal et al:: Non-small cell lung cancer cells survived ionizing radiation treatment display cancer stem cell and epithelial-mesenchymal transition phenotypes. Molecular Cancer 2013 12:94.

\section{Submit your next manuscript to BioMed Central and take full advantage of:}

- Convenient online submission

- Thorough peer review

- No space constraints or color figure charges

- Immediate publication on acceptance

- Inclusion in PubMed, CAS, Scopus and Google Scholar

- Research which is freely available for redistribution

Submit your manuscript at www.biomedcentral.com/submit
Ciomed Central 